\title{
A hydrological analysis of the 4 November 2011 event in Genoa
}

\author{
F. Silvestro ${ }^{1}$, S. Gabellani ${ }^{1}$, F. Giannoni ${ }^{2}$, A. Parodi ${ }^{1}$, N. Rebora ${ }^{1}$, R. Rudari ${ }^{1}$, and F. Siccardi ${ }^{1,3}$ \\ ${ }^{1}$ CIMA Research Foundation, Savona, Italy \\ ${ }^{2}$ ARPAL Regional Environment Protection Agency, Genova, Italy \\ ${ }^{3}$ University of Genova, Genova, Italy \\ Correspondence to: F. Silvestro (francesco.silvestro@cimafoundation.org)
}

Received: 18 April 2012 - Revised: 29 June 2012 - Accepted: 11 July 2012 - Published: 3 September 2012

\begin{abstract}
On the 4 November 2011 a flash flood event hit the area of Genoa with dramatic consequences. Such an event represents, from the meteorological and hydrological perspective, a paradigm of flash floods in the Mediterranean environment.

The hydro-meteorological probabilistic forecasting system for small and medium size catchments in use at the Civil Protection Centre of Liguria region exhibited excellent performances for the event, by predicting, 24-48 $\mathrm{h}$ in advance, the potential level of risk associated with the forecast. It greatly helped the decision makers in issuing a timely and correct alert.

In this work we present the operational outputs of the system provided during the Liguria events and the post event hydrological modelling analysis that has been carried out accounting also for the crowd sourcing information and data. We discuss the benefit of the implemented probabilistic systems for decision-making under uncertainty, highlighting how, in this case, the multi-catchment approach used for predicting floods in small basins has been crucial.
\end{abstract}

\section{Introduction}

In the course of a about two weeks, from 25 October to 4 November 2011, two devastating flooding events affected the Liguria region in northern Italy, causing the death of 19 people and damages of tens of millions of euro to infrastructures, buildings, private and public goods. Some small towns changed their appearance and it has been estimated that, in some cases, several years are needed to return to the conditions prior to the flood.

The two events had some similar characteristics: they were both characterized by the formation of a well organized, very intense and localized finger-shape mesoscale convective system (MCS) - like precipitation structure - embedded within a general stormy synoptic weather scenario developed by a large Mediterranean perturbation. These convective fingers remained stationary for a significant number of hours on the same area (of few square kilometres) pouring very high quantities of rainfall.

The meteoradar images, for the two events, recorded very similar shapes of such small intense structures. They both developed on the sea some tens of kilometres from the coast. They were very narrow and elongated towards the mainland Appennine range. Moving few kilometres outside the "shadow" of the finger-shaped MCS, the rainfall depth, at event time scale, was reduced by a factor two or three.

The hydrological consequences in terms of basin response were dramatic. Many creeks overflowed their banks and a large number of mud flows and landslides occurred in the quite narrow area hit by each event.

The technical authorities in charge of hydrometeorological forecast for the Liguria region predicted the scenarios with a lead-time of two days. The regional civil protection issued the maximum level of alert for most of the region including the catchments eventually hit by the events.

Without the above mentioned warning the number of casualties would have been very high, given the intensity and the suddenness of the hydrological events. The issued alert might have reduced the casualties in both events, but in the end the death toll was unacceptably high. An efficient forecasting system and a skilled civil protection authority issuing general warning, is not enough to avoid casualties. If the population does not adequately perceive the risk condition, at all levels, from elected authorities to citizens, and do not accept to behave differently than usual in case of alert, it is very difficult to reduce human losses to zero. 


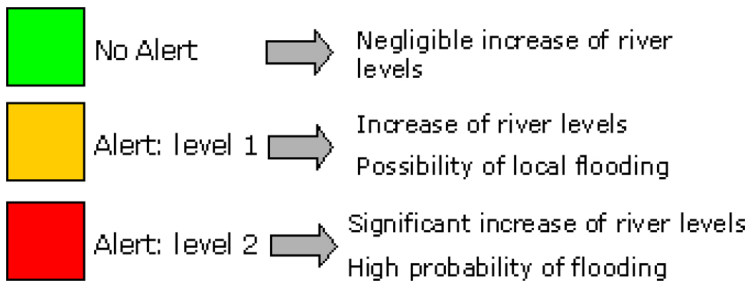

Fig. 1. Synthetic scheme of the alert levels in Liguria region and the related expected consequences.

For sake of synthesis this work is focused on the 4 November event. The previous event, on eastern Liguria, had the same characteristics. The November event affected the central part of Liguria region and the city of Genoa. The Bisagno creek and one of its small tributaries, the Fereggiano brook, developed the most severe ground effects.

In the following paragraphs we run over the chronicle of this case study from a hydrological perspective. The results of the forecasting system are shown, together with the interpretation of the decision makers. The usefulness of a probabilistic flood forecasting chain that contemplates also the multi-catchment approach (Siccardi et al., 2005; Silvestro et al., 2011) is made evident. The event's ground effects are also estimated by using crowd sourcing information and data, in order to check, also by use of recorded ground effects, the granularity of the atmospheric event. The technique of crowdsourcing was quite useful in defining the extension of ground effects. In this paper crowdsourcing is understood as the process that involves outsourcing tasks; in this case the task of documenting freely an event to a distributed group of people, in this case the population of a city or part of a city affected by a flood. It is not a traditional post flood survey, by interviews or collection of images (Marchi et al., 2009). Crowdsourcing mainly relies, in nearly real time, on images or videos distributed on the Internet by real time eyewitnesses.

The article is organized as follows: in Sect. 2 the study area and the hydrometeorological forecasting system are described, Sect. 3 provides a meteorological description of the event, the results of the forecast system and the chronicle of the facts in terms of hydrological modelling and ground effects evaluation. In Sect. 4 discussion and conclusions are presented.

\section{Methods}

\subsection{The civil protection system for the hydro-meteorological risk forecast}

In the Italian civil protection system, the regional offices have the responsibility for issuing alert messages related to natural hazards including severe precipitation events. Techni$\mathrm{cal} / \mathrm{scientific} \mathrm{units,} \mathrm{named} \mathrm{Functional} \mathrm{Centers} \mathrm{(FC),} \mathrm{assist} \mathrm{the}$

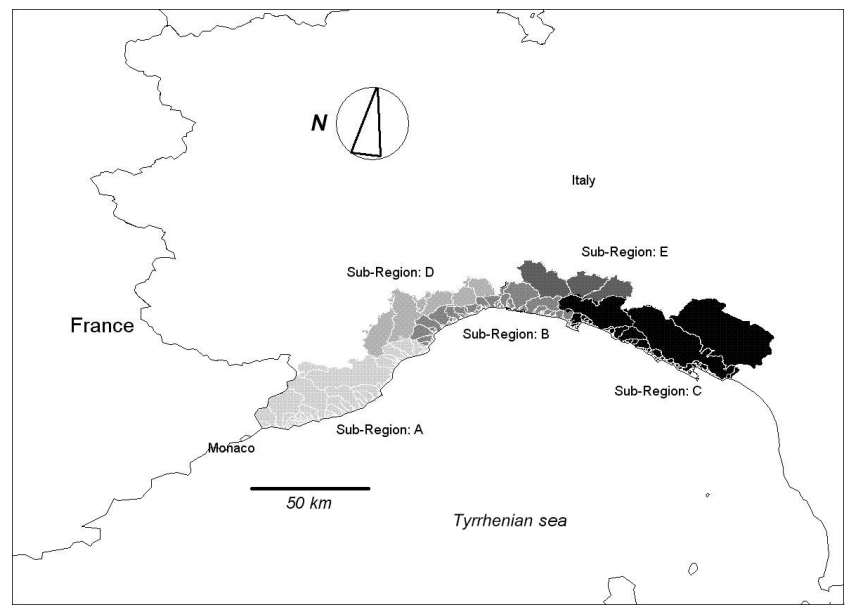

Fig. 2. Study area. In different grey tones the five alert sub-regions of Liguria are shown, together with the watershed of the main basins.

regional offices. In the case of Liguria region the $\mathrm{FC}$ is the local Hydro-Meteorological Monitoring Centre (CFMI-PC). CFMI-PC is in charge of hydrometeorological forecasts. It also carries the responsibility of nowcasting and monitoring rainfall events.

The civil protection of Liguria region has two levels of warning for hydro meteorological risk: Alert 1 and Alert 2. The Alert 2 is the most dangerous level and the related scenario carries really severe rainfall events with associated flooding (Fig. 1). The issuing of an Alert 2 message contemplates that all the actors of the civil protection (and mainly the municipalities) implement a number of predefined procedures for the safeguard of people and goods. The population is requested to behave following a series of simple and practical measures for auto-protection. This level of alert presumes that a very severe event is predicted and it is issued for the whole Liguria region no more than $2-3$ times in a year.

Liguria is divided into five alert sub-regions (Fig. 2), considered homogeneous from a meteorological point of view. They are divided into two groups: one group, south of the Apennines divide, has three sub-regions with basins that have their outlets in the Tyrrhenian Sea. The other group has two sub-regions, they include head basins of the greater catchments that form the Po River, draining to the Adriatic Sea.

The average size of the catchments included within the alert sub-regions is in the order of ten-one hundred $\mathrm{km}^{2}$ on the south and slightly larger on the north.

\subsection{The meteorological networks}

Three different local raingauge networks, with different timing and different working time, were available during this event, together with the precipitation estimation available through the Italian National Radar Composite managed by the Italian Department of Civil Protection (DPC). 
The first raingauge network available, named OMIRL, is the official network managed by the Civil Protection Agency of Liguria region and part of the Italian Raingauge Network of the Italian Civil Protection Department (Molini et al., 2009). This system provides raingauge measurements with a timestep of $5 \mathrm{~min}$ and an average density of 1 raingauge $/ 40 \mathrm{~km}^{2}$ and a total number of about 150 instruments. The municipality of Genova has set up the second network available; it is quite dense but it covers only the city and its inland, the timestep is $3 \mathrm{~min}$. The third network available is the network set up and managed by a non-professional meteorologists association named LIMET (Associazione Ligure di Meteorologia) in Liguria region. LIMET provides raingauge observations freely available over the Internet at the Web-Site http://www.centrometeoligure.it/, the timestep is from 1 to $5 \mathrm{~min}$. The density of this network is highly variable across the Regional territory with denser spots in urban areas where Internet high-speed connection and the availability of power supply make it easier to instal the raingauges. The three networks use different tools, OMIRL uses professional, WMO compliant (accuracy 1-2\%), systematically maintained raingauges, while the LIMET and Municipality networks are composed mainly by low-cost, semiprofessional, albeit reliable raingauges with an accuracy in the range $2-4 \%$. Despite the differences in the instrumentation, the three networks generally give reliable measurements. Data for rain gauge stations of LIMET and municipality networks located in the Fereggiano basin have been checked and corrected for systematic errors, after the event, by the WMO/CIMO Lead Centre "B. Castelli" on Precipitation Intensity at the University of Genoa.

From this point on we will call in the following N1 the first ground network, N2 the second and N3 the third, whilst we will call RC the radar composite.

Observations from N1, N2 and N3 will be used alone and together for a better definition of the total amount of rainfall that hit the Bisagno creek and the Fereggiano brook.

The Italian National Radar Composite integrates the regional system, made up of ten C-band radars (five of them polarimetric) and one transportable X-band polarimetric radar, two systems owned by the Italian company for air navigation services (ENAV), and three managed by the Meteorological Department of the Italian Air Force (AMI). The composite is provided both in terms of radar reflectivity, surface rainfall intensity and surface rain depth with a time step of $15 \mathrm{~min}$ and a spatial resolution of $1 \mathrm{~km}$. During the Genoa event, unfortunately, the closest radar of the network was not running due to technical problems. The observations made by the other radar covering the area gave estimates of the spatial structure of the event. Due to the long distance and to the attenuation, it was not possible in real-time to correctly define the precipitation amount.

\subsection{The hydrometeorological forecasting chain}

As described in Silvestro et al. (2011), the precipitation forecast for the Liguria region is provided by a number of numerical weather prediction models (NWP) and interpreted by expert meteorologists. The experts merge the output of the different meteorological models (the so called "poor man ensemble") with their own experience and provide quantitative precipitation forecast on the alert sub-regions on predefined time windows. For each alert sub-region a different quantitative precipitation forecast is made. This kind of expert forecast is locally named "subjective forecast".

The subjective precipitation forecast is used as input into the operational probabilistic hydro-meteorological forecasting chain (Siccardi et al., 2005; Silvestro et al., 2011). The other components of the hydro-meteorological chain are the downscaling module RainFARM (Rebora et al., 2006), and the hydrological model DRiFt (Giannoni et al., 2005; Gabellani et al., 2008).

The downscaling module produces high-resolution precipitation fields, say one hundred, by preserving the information at large scale derived from a quantitative precipitation prediction and it is in this way able to generate one hundred "universes" with small scale structures of precipitation that are consistent with radar observations of mid-latitude precipitation events (Rebora et al., 2006). Each of the one hundred precipitation fields is then used as input into the hydrological model of each catchment, down to scales of the square kilometer, in order to generate one hundred streamflow scenarios on each catchment. The results are post-processed producing a flood prediction following two different approaches: the single-site and the multi-catchment (Siccardi et al., 2005).

The single site approach is applied to all the modelled basins, but is mainly useful for those basins that have an area larger than 200-300 km² (Silvestro et al., 2011). In this case, the probability that a certain flow threshold (or the flow with given return period $T$ ) could be exceeded is directly evaluated.

For smaller basins a different approach is followed, because the ratio between the reliable spatial-temporal scale $\left(l_{\mathrm{met}}, t_{\mathrm{met}}\right)$ of the meteorological forecast and the scales of the hydrological processes ( $l_{\text {hydro }}, t_{\text {hydro }}$ ) is too large $\left(\mathrm{O}\left(l_{\text {met }} / l_{\text {hydro }}\right)>10^{2}\right)$. As a consequence, the forecasting procedure does not allow for any discrimination between different spatial localization. We thus cannot consider every single basin as an independent entity but we consider all the basins together inside the domain of $l_{\text {met }}$ size.

In the case of Liguria region forecasting chain, the domain of $l_{\text {met }}$ size is assumed to be the alert sub-region. For each alert sub-region a different forecast is produced. The procedure evaluates the probability that, in at least one basin belonging to that specific alert sub-region, the flow with given return period $T$ will be exceeded. The procedure does not specify which basin will be stricken, due to the uncertainty associated to the meteorological forecast. Such a procedure 


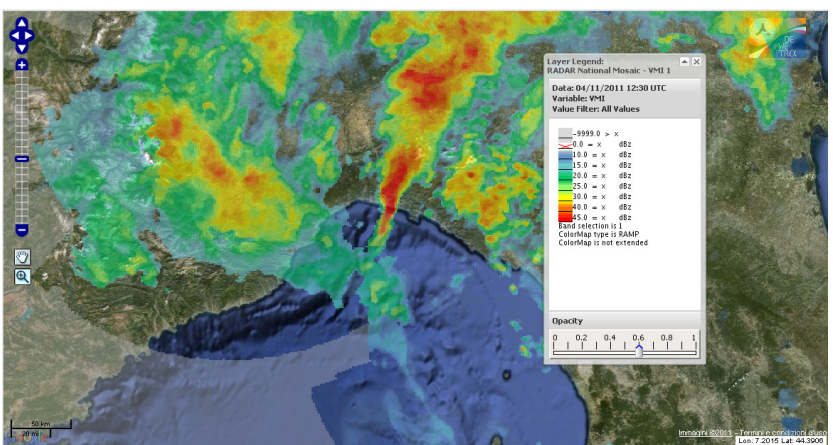

Fig. 3. Finger-like isolated auto-regenerating MCS in front of the Genoa coast on 4 November at 12:30 UTC (Maximum Vertical Reflectivity, RC).

is called a multi-catchment approach (Siccardi et al., 2005) and represents an essential paradigm in the case of flood forecasts in very small basins both for the scientific and political levels involved in the civil protection decision mechanism; it has been the crucial element in the prediction of the event of 4 November 2011 in Genoa.

\section{The case study}

\subsection{Meteorological description}

The heavy rainfall that triggered the deadly flooding of Genova was the most powerful event embedded in a larger system that persisted on Southern Europe for almost a week, from 3 November to 8 November. The extra tropical macrostorm originated from the extension of the 2011 "Halloween Nor'easter" that brought early heavy snowfall on Central and Eastern US in the last day of October. This system, coming across the Atlantic Ocean, regained strength by combining with the remnants of the tropical storm Rina (2328 October, Yucatan and Cuba). Its precipitable water content was strongly enhanced. The system found also a very warm Mediterranean, with sea surface temperature (SST) anomaly values, with respect to the last $20 \mathrm{yr}$, around 1.0 $1.5^{\circ} \mathrm{C}$. This was responsible for enhancing the latent and sensible heat fluxes from the sea to the lowest portion of the planetary boundary layer. Both effects continued to increase the potential severity of the cyclone. An upper-level cold low, centred north-west of Ireland and extended meridionally to the Iberian Peninsula, established an intense and moist stream flow from the south/southeast impinging against Liguria Apennines ridge. The Apennines divide exceeds $1500 \mathrm{~m}$ in a very short distance from the sea. The west of Liguria was mainly affected by widespread rains, while the heavy rainfall was concentrated in the centre of the region over the city centre of Genoa, extending to the west due to a strong convergence of the flow of Sirocco wind (warm, humid airflow moving to the northwest).
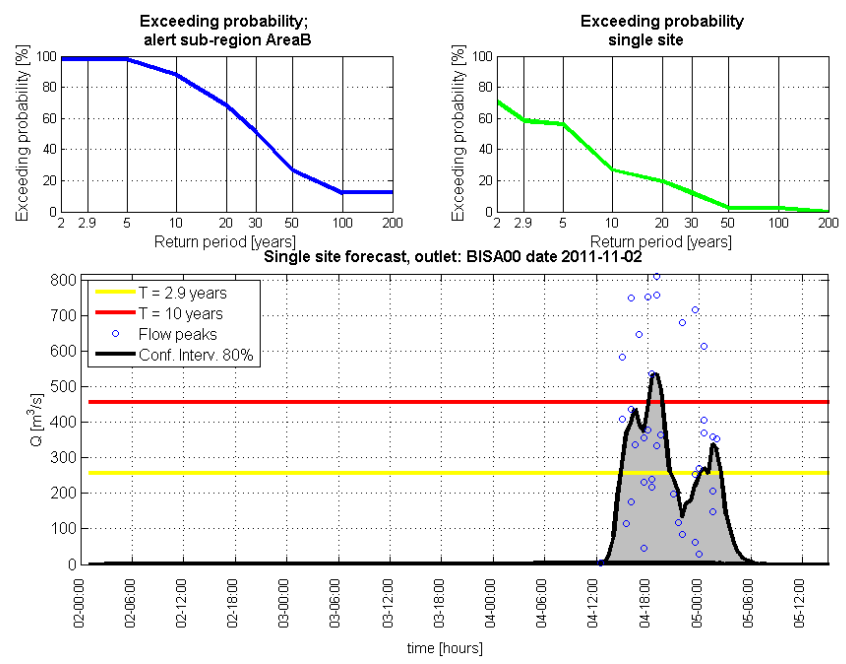

Fig. 4. Results of the operational probabilistic flood forecasting chain with the subjective precipitation forecast as meteorological input - Bisagno creek near the mouth $\left(90 \mathrm{~km}^{2}\right)$. The lower panel shows the $80 \%$ confidence intervals of forecast discharge and the forecast peak flows. On the X-axis, the UTC time is reported. Note that the lower confidence bound is nearly zero. The top right panel shows the exceedance probability of the flow with return period $T$ as function of $T$ for the single site approach (Bisagno catchment). For purposes of comparison, the top left panel shows the exceedance probability of the flow with return period $T$ in function of $T$ for the multi-catchment approach in the alert sub-region containing the Bisagno catchment.

At the $\gamma$-mesoscale, the torrential event was associated with the aforementioned finger-like, isolated and selfregenerating MCS convective cell triggered in the Gulf of Genoa on the night of 4 November (01:00-02:00 UTC), as observed by the RC (Fig. 3). The cell started wandering along the eastern coast (03:00-09:00 UTC) of Liguria and finally was stuck over the western portion of Genoa hills producing very high rainfall depth.

\subsection{The forecast}

The scenario that the hydro-meteorologists of CFMI-PC drew for the 2 November 2011 was that of a large perturbation with great amounts of precipitation that would affect the central and the western part of the region on 4 and 5 November. Really intense rainfall on small spatial and temporal scales was also forecasted.

The probabilistic hydro-meteorological chain pointed out that the effects in terms of flooding could have been calamitous.

Figure 4 shows the 2 November hydrological prediction for the Bisagno creek (area of $90 \mathrm{~km}^{2}$ ). The lower panel shows the $80 \%$ confidence intervals of predicted discharge and the predicted peak flows. The lower confidence bound is 


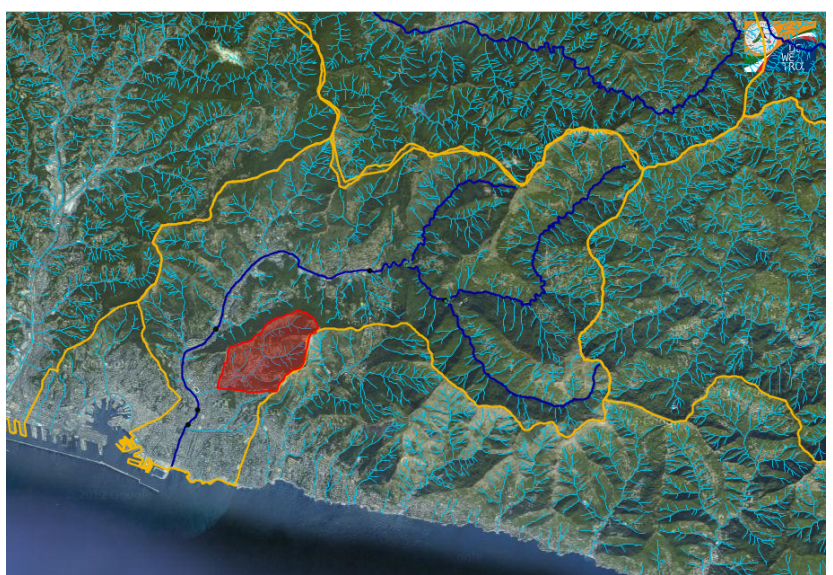

Fig. 5. Bisagno creek (blue line and yellow watershed, Area $=$ $90 \mathrm{~km}^{2}$ ) and its tributary Fereggiano brook (red area, Area $=$ $4.5 \mathrm{~km}^{2}$ ).

nearly zero. The spread is large and the probability to exceed the return period $T=10 \mathrm{yr}$ is about $30 \%$.

The top right panel shows the exceedance probability of the flow with return period $T$ as function of $T$ for the single site approach. For purposes of comparison, the top left panel shows the exceedance probability of the flow with return period $T$ in function of $T$ for the multi catchment approach in the alert sub-region containing the Bisagno catchment. In the latter the probability to overcome the $T=5 \mathrm{yr}$ return period is about $100 \%$ and is $50 \%$ for $T=30 \mathrm{yr}$. Moreover, a significant probability to exceed the flow with return period $T=100 \mathrm{yr}$ (about $15 \%$ ) is also showed in the prediction. This result warned the civil protection officers that in one or more basins, within the sub-region, the probability of having a flood event was high.

The results of the forecasting chain and the evaluation of CFMI-PC experts lead the civil protection of Liguria region to issue the highest alert level for the alert area B two days in advance.

\subsection{The facts}

\subsubsection{Study area}

The most disastrous effects were due to the flooding of Bisagno creek and Fereggiano brook (Fig. 5). They both cross the city centre of Genoa in a really densely urbanized area. The city develops along the Bisagno creek for about $10 \mathrm{~km}$ inland. The final reach is constricted between two parallel avenues. Along the last $1.5 \mathrm{~km}$ till to the mouth the river flows under a cover. The maximum flow carried without risk, i.e. in conditions of free surface flow, under the cover is between 500 and $700 \mathrm{~m}^{3} \mathrm{~s}^{-1}(15 \mathrm{yr}<T<30 \mathrm{yr})$. For discharge values exceeding such limits, the flow changes suddenly from the condition of free surface flow to the condition of pressure flow. If and when the transition happens the discharge

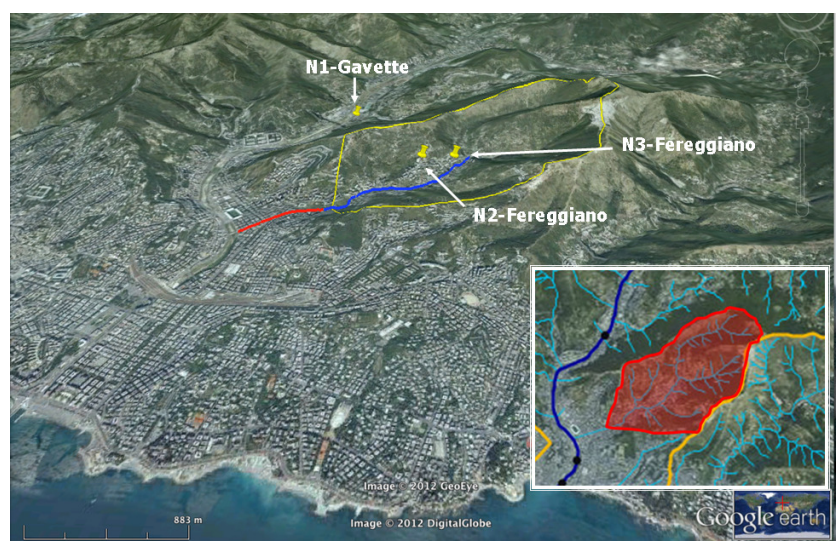

Fig. 6. Location of the three analysed rain gauges: the blue and red line shows the Fereggiano riverbed, in red the covered reach. The yellow line is the watershed divide. On the bottom right corner the Fereggiano watershed is shown together with its drainage network.

carried under the cover is suddenly reduced. The difference overflows and a sudden inundation of the urban areas takes place.

The Fereggiano brook is the last tributary of the Bisagno creek on the left. The catchment has an area of about $4.5 \mathrm{~km}^{2}$ and it is densely populated (thousand for $\mathrm{km}^{2}$ ). In the last $600 \mathrm{~m}$ the Fereggiano flows under a cover. The estimated $50 \mathrm{yr}$ return period discharge (about $85 \mathrm{~m}^{3} \mathrm{~s}^{-1}$ ) can not be carried under the cover (Provincial Authority of Genoa, 2001). The maximum flow carried in the condition of free surface flow is about $70 \mathrm{~m}^{3} \mathrm{~s}^{-1}$. When the flow reaches the intrados of the cover, the flow rate is reduced to about $50 \mathrm{~m}^{3} \mathrm{~s}^{-1}$.

The growth of the city over the final reaches of the Bisagno creek and the Fereggiano brook during the second part of the century created hydraulic conditions prone to disastrous floods (Brandolini et al., 2012).

\subsubsection{Precipitation analysis}

In the study area the rain gauge density is really high because of the presence of stations belonging to all three rain gauge networks described in Sect. 2.2. We analysed the data of three stations located in the area where the most dramatic effects occurred. As can be seen by Fig. 6 they are close together, there are about $300 \mathrm{~m}$ between N3-Fereggiano and N2-Fereggiano stations, and less than $2 \mathrm{~km}$ between N3-Fereggiano, N2-Fereggiano and the N1-Gavette. Despite the proximity, there are not negligible differences between N2-Fereggiano, N3-Fereggiano and N1-Gavette simultaneous measurements (Fig. 7). This is due only to rainfall spatial variability. In fact, because such variability was large, a check on the instruments was made after the event by using the methodology described in (Lanza and Vuerich, 2009). Revised measurements are available and used for the 


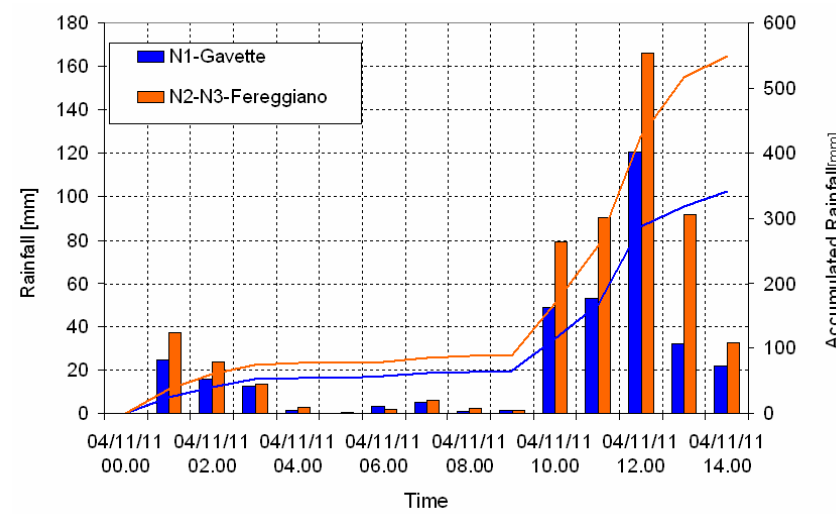

Fig. 7. 4 November 2011. Comparison of three rain gauges located inside or close to the Fereggiano brook at an hourly resolution. On left $y$-axis hourly rainfall, on right $y$-axis accumulated rainfall. On $\mathrm{x}$-axis, the UTC time is reported. N1-Gavette, courtesy of the Liguria Civil Protection Agency; N2-Fereggiano, courtesy of the Liguria Civil Protection Agency and Municipality of Genova; and N3Fereggiano, courtesy of the Ligurian Association of Meteorology.

analysis. After the correction of the data from N2 and N3 stations, there is a very good agreement between the two rainfall time-series. We use the notation N2-N3-Fereggiano to indicate data valid for both raingauges available on the Fereggiano brook.

To provide an estimation of the return period $T$ of the precipitation, three approaches have been followed. Two are single site analysis based on the historical data series of the N1-Gavette station. The analysis has been carried out using the Gumbel and the GEV (De Michele and Rosso, 2001; Burlando and Rosso, 1996) cumulative distribution functions (CDF). The third approach is from a regional analysis made with data series from 1930 to 1992 (Boni 2000). The Gumbel and GEV methods are applied using a more recent data sample of about forty years including precipitation data from 1992 to 2011 that where evidently not available when the regional analysis was performed. The results are reported in Table 1 and Fig. 8 and, as can be noted, the estimation of $T$ varies depending on the applied method and its uncertainty is sometimes really high.

The inspection of Fig. 8 clearly reveals that the rain depth recorded for the durations of one, three and six hours is a rare event, very rare if compared with the regional analysis and slightly less rare in the more recent single site analysis.

\subsubsection{Bisagno creek}

In order to check the granularity of the rainfall and the relative rarity of the event also from the point of view of the ground effects, the hydrograph produced in the Bisagno creek and the Fereggiano brook has been simulated and compared with the observations. The streamflow has been simulated using the hydrological model DRiFt (Giannoni et al.,
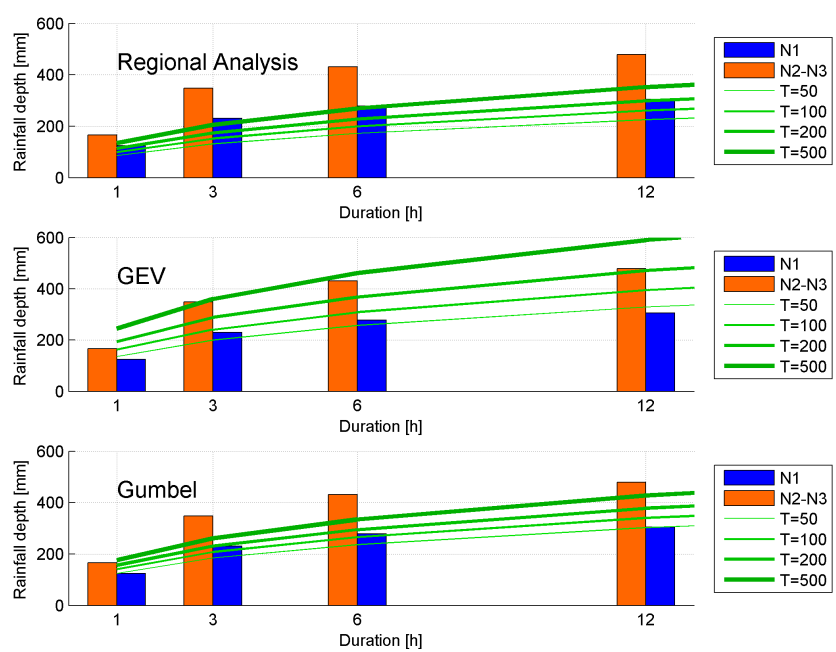

Fig. 8. Depth-duration-frequency curves obtained through the three applied approaches (GEV and Gumbel site analysis and Regional Analysis). N1 stands for N1-Gavette, N2-N3 stands for N2-N3Fereggiano.

2005; Gabellani et al., 2008) that is operational in most of the Liguria basins. The simulations have been carried out by setting three different configurations depending on the rainfall data used as input to the model:

- Configuration A: data from the N1 network only (operational configuration).

- Configuration B: data from network N1 integrated with the stations belonging to the $\mathrm{N} 2$ or $\mathrm{N} 3$ network.

The results are reported in Fig. 9 for the Bisagno creek. The shape of the three hydrographs are really similar, but the peak flows largely vary with the different sets of input data; using only N1 data, the peak flow is about $610 \mathrm{~m}^{3} \mathrm{~s}^{-1}$, while using measurements from $\mathrm{N} 2$ or $\mathrm{N} 3$ network, the peaks are very similar, about $750 \mathrm{~m}^{3} \mathrm{~s}^{-1}$. In Table 2 the return periods of the simulated peak flows derived using Boni et al. (2007) are reported. The three peak flow values show $\mathrm{T}$ between 20 and $30 \mathrm{yr}$ and they are close to the limit value for flooding, this limit has been surely reached since Bisagno flooded. The latter is key information to confirming the reliability of the simulation.

\subsubsection{Fereggiano brook}

In the case of Fereggiano brook the streamflow has been simulated with a simplified rainfall-runoff model that couple the SCS-Curve Number (CN) method (United States Department of Agriculture, 1954) for infiltration estimation with the Nash Instantaneous Unit Hydrograph (Nash, 1957) for discharge calculation. The value of basin scale average $\mathrm{CN}$ is 75 and it has been estimated based on a distributed curve number map 
Table 1. Return period $T$ of the rain depth observed, during four standard durations by the three rain gauges presented in Fig. 6 , as estimated following the three different methods highlighted in the text.

\begin{tabular}{llrrrr}
\hline $\begin{array}{l}\text { Duration } \\
\text { (h) }\end{array}$ & Station & $\begin{array}{c}\text { Rainfall } \\
(\mathrm{mm})\end{array}$ & $\begin{array}{r}T(\mathrm{yr}) \\
\text { Regional Analysis } \\
\text { (data from 1930 to 1992) }\end{array}$ & $\begin{array}{r}T \text { (yr) } \\
\text { GEV (data from } \\
1950 \text { to 2011) }\end{array}$ & $\begin{array}{r}T(\mathrm{yr}) \\
\text { Gumbel (data from } \\
1950 \text { to 2011) }\end{array}$ \\
\hline 1 & & 124 & 100 & 35 & 50 \\
3 & 230 & 300 & 80 & 200 \\
6 & N1-Gavette & 278 & 200 & 70 & 130 \\
12 & & 305 & 7500 & 40 & 50 \\
1 & 166 & $>500$ & 400 & 250 \\
3 & & $>500$ & 400 & $>500$ \\
6 & N2-N3-Fereggiano & 448 & $>500$ & 200 & $>500$ \\
12 & & 479 & & 500 \\
\hline
\end{tabular}

Table 2. Return period of the peak flows simulated for Bisagno creek using the three different input configurations.

\begin{tabular}{lll}
\hline Configuration & $Q\left(\mathrm{~m}^{3} \mathrm{~s}^{-1}\right)$ & $T(\mathrm{yr})$ \\
\hline $\mathrm{N} 1$ & 610 & $\cong 20$ \\
$\mathrm{~N} 1+\mathrm{N} 2$ or $\mathrm{N} 1+\mathrm{N} 3$ & $\cong 750$ & $\cong 30$ \\
\hline
\end{tabular}

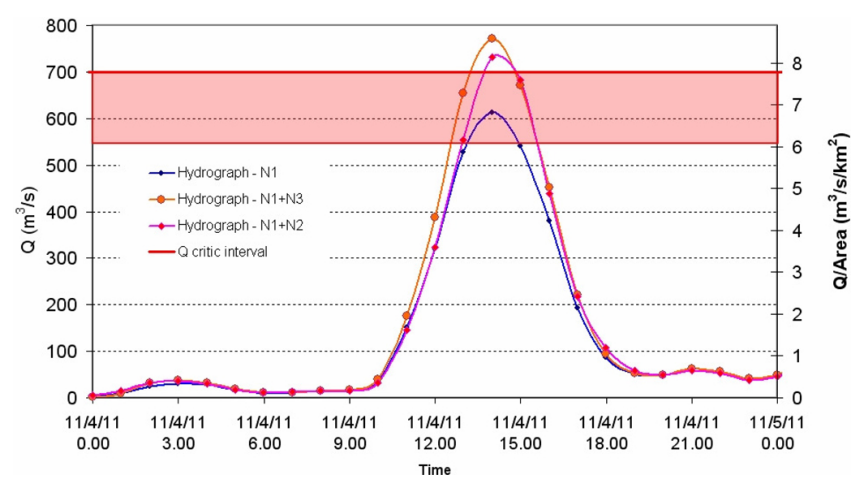

Fig. 9. Bisagno creek. Simulations with different meteorological networks. $Q_{\text {critic }}$ is the maximum streamflow that can flow under the cover. On the left y-axis the streamflow is reported while on the right $y$-axis the flow contribution per unit area is shown. On $\mathrm{x}$-axis the UTC time is reported.

available for the region. The value is quite high due to the very high percentage of urbanized surface in the basin.

The simulations have been carried out setting only two different configurations (see considerations about the rain gauges in Sect. 3.3.2) depending on the rainfall data used as an input to the model:

- Configuration A: data from the N1-Gavette station of the official network which is located about $1.5 \mathrm{~km}$ from the stations N2-Fereggiano and N3-Fereggiano, just on top of the catchment used in configuration $\mathrm{B}$.

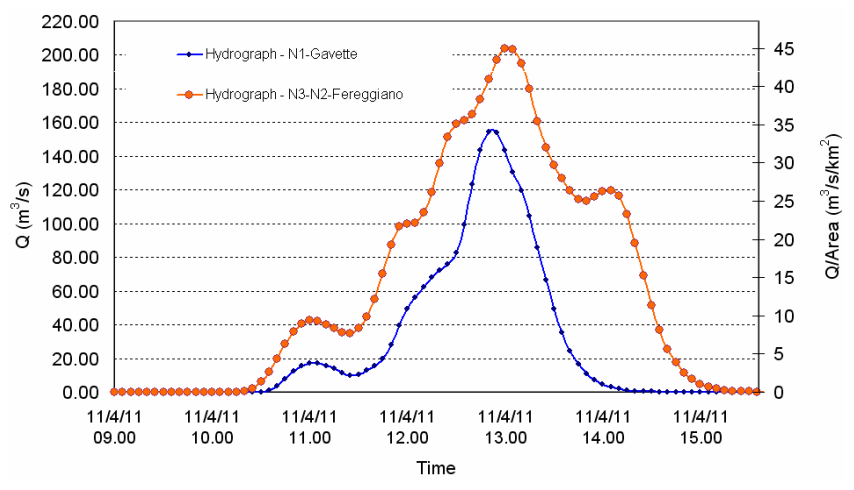

Fig. 10. Fereggiano brook. Flow simulations. On the left y-axis the streamflow is reported while on the right $y$-axis the flow contribution per unit area is shown. On $\mathrm{x}$-axis the UTC time is reported.

- Configuration B: data from the N3-Fereggiano station located on top of the Fereggiano brook catchment. This is also representative of the N2-Fereggiano station.

Figure 10 reports the results of the simulations. The differences between the hydrographs are due to two main reasons:

- Rainfall depth on a 5 min time step can significantly vary between near gauges due to the spatial variability of precipitation. This has a great impact on the streamflow simulation on small basins;

- As already pointed out, the N3-Fereggiano gauge was just on the centre of the downpour. It recorded a rain depth significantly larger than the N1-Gavette station. As a consequence the total runoff volume is larger.

The estimated peak flow is in the range of $160 \mathrm{~m}^{3} \mathrm{~s}^{-1}$ $200 \mathrm{~m}^{3} \mathrm{~s}^{-1}$, while the maximum flow that can be drained under the cover is about $70 \mathrm{~m}^{3} \mathrm{~s}^{-1}$ in case of free surface flow and about $50 \mathrm{~m}^{3} \mathrm{~s}^{-1}$ in case of pressure flow. A large part of the discharge did overflow above the cover (Fig. 11). A lot of videos taken by the citizens show the street above the 


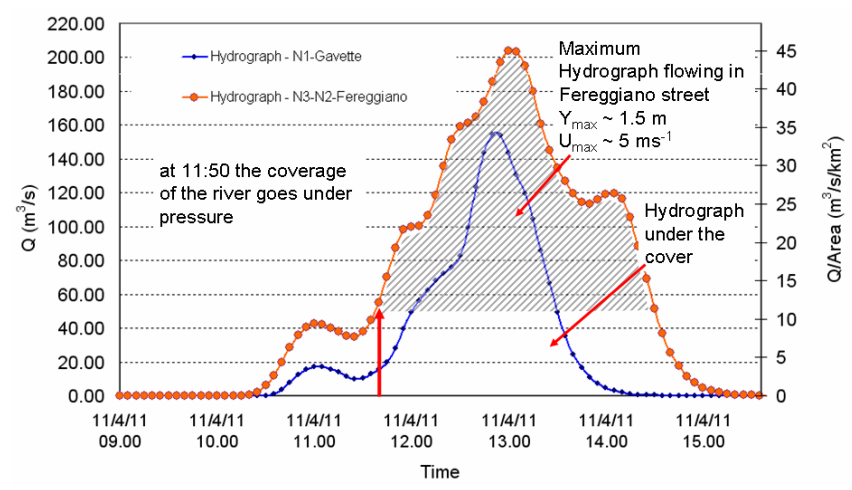

Fig. 11. Fereggiano brook. Flood scenario interpretation using the hydrograph estimated by using the different Rain Gauge stations. On $\mathrm{x}$-axis the UTC time is reported.

cover filled with water flowing at high velocity. Six people died; many stores, restaurants and small firms were damaged as well as a large number of cars.

The estimation of the return period $T$ associated with the peak flow is highly uncertain. In the river basin planning (Provincial Authority of Genoa, 2001) the flows with fixed $T$ are estimated: $Q(T=50 \mathrm{yr})=85 \mathrm{~m}^{3} \mathrm{~s}^{-1}, Q(T=200 \mathrm{yr})=$ $140 \mathrm{~m}^{3} \mathrm{~s}^{-1}, Q(T=500 \mathrm{yr})=190 \mathrm{~m}^{3} \mathrm{~s}^{-1}$.

The simulated peak flows have the return periods shown in Table 3.

As can be noticed in comparing Figs. 9 and 10, the flow contribution per unit area of Fereggiano brook is considerably larger than that of the Bisagno creek. This highlights how the most intense core of the rainfall event was localized in a reduced area and it affected a very narrow ground strip. This also reflects the fact that the estimated return periods $T$ of the two peak flows are very different, even if both are very rare events. Considering Figs. 9 and 11, it is clear that the percentage of the hydrograph that overflowed is largely different in the two cases. In the case of Bisagno creek, the inundation volume (around $0.7 \mathrm{mil} . \mathrm{m}^{3}$ estimated with the configuration C) was $3-4 \%$ of the total flood volume, while in the case of Fereggiano brook (around 8.5 mil. $\mathrm{m}^{3}$ estimated with the configuration $\mathrm{B}$ ) the percentage is $45-48 \%$.

The experimental evidence and the crowd sourcing information (videos, photos, tracks on the buildings) compared with hydraulic simulations confirms that the level of water that has been reached corresponds to discharge flow with $T$ surely larger than $50 \mathrm{yr}$. Using both this information and considering the two simulations equally reliable, we could state that the occurred peak flow had reasonably a $T$ higher than $200 \mathrm{yr}$.

Another hydraulic verification has been made by checking a video made by a citizen during the flooding and available in near real time on www.youtube.com. The video clearly shows that the level of water reaches the height of the banks, the flow hits an obstacle and its kinetic energy transforms
Table 3. Return period of the peak flows simulated for Fereggiano brook using the two different rainfall inputs to feed the hydrological model.

\begin{tabular}{lll}
\hline Configuration & $Q\left(\mathrm{~m}^{3} \mathrm{~s}^{-1}\right)$ & $T(\mathrm{yr})$ \\
\hline N1-Gavette & $\cong 160$ & $200<T<500$ \\
N3-Fereggiano & $\cong 200$ & $T \cong 500$ \\
\hline
\end{tabular}

into potential energy generating a sort of water jet in the vertical direction of about $1 \mathrm{~m}$. The velocity of the flow (around that point) can be estimated:

$V=\sqrt{2 \cdot g \cdot h} \cong 5 \mathrm{~m} \mathrm{~s}^{-1}$.

Assuming a mean velocity of $4-5 \mathrm{~m} \mathrm{~s}^{-1}$ for the cross section and estimating the area of the wet cross section from the video and from direct inspection, it is possible to estimate the flow as

$Q \cong 100-120 \mathrm{~m}^{3} \mathrm{~s}^{-1}$.

The video refers to times between 12:00 and 12:30 on 4 November. By looking at Figs. 9 and 11 it is possible to verify that the simulated flow is quite realistic.

\section{Conclusions}

The flooding event occurred on the 4 November 2011 that hit the central part of Liguria Italian region has been analysed from a hydrological point of view. The results of the official forecast system have been shown, demonstrating how they helped the hydro-meteorologists and the decision makers who, valuing also their experience and the knowledge of the morpho-climatic characteristics of the study area, recognized the severity of the event and issued the maximum level of alert with large anticipation.

The rainfall event was very localized, a large amount of precipitation fell in an area of few square kilometres with high intensities in about 5-6h. Flooding occurred on two small basins that cross the city of Genova (Bisagno creek and Fereggiano brook) while in most of the neighbouring catchments there have been only reduced effects. These kinds of events, which are quite common in Mediterranean area, can be hardly forecasted by the Numerical Weather Prediction Systems; the flood forecast can only be probabilistic, and the use of downscaling methodologies remains essential. Moreover, for such small basins the multi-catchment approach (Siccardi et al., 2005) is fundamental. In such an environment, made by a collection of very small catchments with enhanced flood risk condition along their streams, decision makers must become familiar with the impossibility of identifying a specific catchment as the target of the warning to be issued: this has an impact both on the type of warning to be issued and the countermeasures to be prepared; more than 
that this concept must be built up in the perception of the citizens that ultimately interpret the flood warnings and apply their auto-protection measures.

The facts on Fereggiano brook evidenced the benefit of applying the multi-catchment approach during the prediction. The multi-catchment approach (see Fig. 4) in fact evidenced non-negligible probabilities of exceedance of flow with $T=$ $50 \mathrm{yr}(P=25 \%), T=100 \mathrm{yr}(P=15 \%)$ and $T=200 \mathrm{yr}$ $(P=15 \%)$, this dreadful forecast effectively occurred (see Fig. 10 and Table 3).

The ground effects have been reconstructed and described by using the abundant rainfall observations, the hydrological modelling and the crowd sourcing information. In particular, the simulations on Fereggiano brook have been verified by using videos made by citizens. The differences among the simulations performed with the official network alone or the one where this was complemented with the additionally available networks has highlighted another limitation posed by the spatial and temporal scale of these types of events. These differences in fact showed how difficult it is to observe a rainfall distribution consistent with the real one and posed the question of how to use in operational and official forecasting systems the wealth of information that comes from common citizens operating monitoring networks in an organized way. This theme has many implications in terms of QA/QC procedures on one side and in terms of liability on the other.

Despite the forecast was correct and the alert message had been issued with large anticipation, the consequences have been terrible and the event claimed six victims. Not all the elements of the Early Warning System worked effectively. Civil protection plans at municipality level were present, but they proved to be not adequate under real stress conditions. Civil protection plans are however essential in limiting human losses only if the population has the right perception of the prefigured scenarios, so that they can implement properly and timely the auto-protection measures once the possible risk conditions are communicated. In this event many people ignored that an alert message was issued, and the majority of people ignored the meaning of that message and behaved as if no risk was pendent. Finally, a relevant number of people (probably not the majority) acted inappropriately, as documented in the many videos shared during the event, enhancing their exposure to the imminent danger.

The analysed event and its consequences remind us of what scientists sometimes tend to underestimate: that an Early Warning System does not stop at only timely and accurate forecasts, but all the civil protection actors must also be adequately prepared and organized, otherwise the work of an efficient pool of forecasters and decision-makers can be nullified. The citizens are a fundamental element: they should be better aware of the risks related to the area where they live and be better prepared to face those risks. The citizens should not perceive themselves as simple "customers" of the civil protection system, but as an active part of the system itself. Along these lines, the authors think that there is the need to involve the citizens in the phase of designing the procedures to be carried out in case of emergency. The increasing availability of handy technology to the large public also poses the challenge of how to exploit at least a part of the citizens as "watchers" of the occurring event as well as data suppliers.

Acknowledgements. This work is supported by the Italian Civil Protection Department and by the Italian Region of Liguria. We acknowledge the Liguria region, the Municipality of Genoa and the LIMET association for providing us with the data from their meteorological observation networks, and the Italian Civil Protection Department for providing us with the data of Italian National Radar Composite. We acknowledge the WMO/CIMO Lead Centre "B. Castelli" on Precipitation Intensity at the University of Genoa for providing us with the checked and corrected data for rain gauge stations of LIMET and Municipality Networks located in the Fereggiano basin. We are very grateful to all the meteorologists and the hydrologists of the Meteo-Hydrologic Centre of Liguria region, for the many useful discussions we had.

Edited by: M.-C. Llasat

Reviewed by: two anonymous referees

\section{References}

Boni, G.: A physically based regional rainfall frequency analysis: application to a coastal region in Northern Italy, EGS Plinius Conf. on Mediterranean Storms, Maratea, 14-16 October 1999, 365-376, 2000.

Boni, G., Ferraris, L., Giannoni, F., Roth, G., and Rudari, R.: Flood probability analysis for un-gauged watersheds by means of a simple distributed hydrologic model, Adv. Water Res., 30, 21352144, doi:10.1016/j.advwatres.2006.08.009, 2007.

Brandolini, P., Cevasco, A., Firpo, M., Robbiano, A., and Sacchini, A.: Geo-hydrological risk management for civil protection purposes in the urban area of Genoa (Liguria, NW Italy), Nat. Hazards Earth Syst. Sci., 12, 943-959, doi:10.5194/nhess-12-9432012, 2012.

Burlando, P. and Rosso, R.: Scaling and multi-scaling models of depth-duration-frequency curves of storm precipitation, J. Hydrol., 187, 45-64, 1996.

De Michele, C. and Rosso, R.: Guidelines for flood frequency estimation in North-Western Italy, FRAMEWORK Final Project, edited by: Rosso, R., Milano, 2001.

Gabellani, S., Silvestro, F., Rudari, R., and Boni, G.: General calibration methodology for a combined Horton-SCS infiltration scheme in flash flood modeling, Nat. Hazards Earth Syst. Sci., 8, 1317-1327, doi:10.5194/nhess-8-1317-2008, 2008.

Giannoni, F., Roth G., and Rudari, R.: A procedure for drainage network identification from geomorphology and its application to the prediction of the hydrologic response, Adv. Water Res., 28, 567-581, doi:10.1016/j.advwatres.2004.11.013, 2005.

Lanza, L. G. and Vuerich, E.: The WMO Field Intercomparison of Rainfall Intensity Gauges, Atmos. Res., 94, 534-543, doi:10.1016/j.atmosres.2009.06.012, 2009.

Marchi, L., Borga, M., Preciso, E., Sangati, M., Gaume, E., Bain, V., Delrieu, G., Bonnifait, L., and Pogancik, N.: Comprehensive 
post-event survey of a flash flood in Western Slovenia: observation strategy and lessons learned, Hydrol. Process., 23, 37613770, doi:10.1002/hyp.7542, 2009.

Molini, L., Parodi, A., and Siccardi, F.: Dealing with uncertainty: an analysis of the severe weather events over Italy in 2006, Nat. Hazards Earth Syst. Sci., 9, 1775-1786, doi:10.5194/nhess-91775-2009, 2009.

Nash, J. E.: The form of instantaneous unit hydrograph, Int. Assoc. Sci. Hydrol., 3, 114-121, 1957.

Provincial Authority of Genoa: River basin planning of the Bisagno creek, available at: http://cartogis.provincia.genova.it/cartogis/ pdb/bisagno (last access: 15 January 2012), 2001.
Rebora, N., Ferraris, L., Hardenberg, J. H., and Provenzale, A.: The RainFARM: Rainfall Downscaling by a Filtered Auto Regressive Model, J. Hydrometeorol., 7, 724-738, 2006.

Siccardi, F., Boni, G., Ferraris, L., and Rudari, R.: A hydrometeorological approach for probabilistic flood forecast, J. Geophys. Res, 110, D05101, doi:10.1029/2004jd005314, 2005.

Silvestro, F., Rebora, N., and Ferraris, L.: Quantitative flood forecasting on small and medium size basins: a probabilistic approach for operational purposes, J. Hydrometeorol., 12, 14321446, 2011.

United States Department of Agriculture: S. C. S.: National Engeneering Handbook, Section 4, US Department of Agriculture, Washington, DC, 1954. 